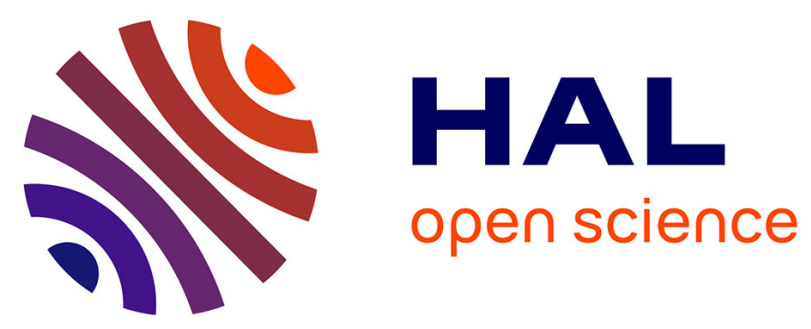

\title{
Geological structures control on earthquake ruptures: The M w 7.7, 2013, Balochistan earthquake, Pakistan
} A. A Vallage, Y. Klinger, R. Lacassin, A. Delorme, M. Pierrot-Deseilligny

\section{To cite this version:}

A. A Vallage, Y. Klinger, R. Lacassin, A. Delorme, M. Pierrot-Deseilligny. Geological structures control on earthquake ruptures: The M w 7.7, 2013, Balochistan earthquake, Pakistan. Geophysical Research Letters, 2016, 43 (19), pp.10,155-10,163. 10.1002/2016gl070418 . insu-01888985

\section{HAL Id: insu-01888985 https://hal-insu.archives-ouvertes.fr/insu-01888985}

Submitted on 5 Oct 2018

HAL is a multi-disciplinary open access archive for the deposit and dissemination of scientific research documents, whether they are published or not. The documents may come from teaching and research institutions in France or abroad, or from public or private research centers.
L'archive ouverte pluridisciplinaire HAL, est destinée au dépôt et à la diffusion de documents scientifiques de niveau recherche, publiés ou non, émanant des établissements d'enseignement et de recherche français ou étrangers, des laboratoires publics ou privés. 


\section{Geophysical Research Letters}

\section{RESEARCH LETTER}

10.1002/2016GL070418

Key Points:

- High-resolution quantification of the 2013 Balochistan earthquake displacement from optical image correlation

- Characterization of the frontal rupture geometry, based on 1:500 scale ground surface rupture mapping, inside the coseismic damage zone

- Preexisting geological structures and state of stress control on earthquake rupture propagation and geometrical complexities

Supporting Information:

- Supporting Information S1

Correspondence to:

A. Vallage,

vallage@ipgp.fr

\section{Citation:}

Vallage, A., Y. Klinger, R. Lacassin, A. Delorme, and M. Pierrot-Deseilligny (2016), Geological structures control on earthquake ruptures: The $M_{w} 7.7,2013$, Balochistan earthquake, Pakistan, Geophys. Res. Lett., 43, 10,155-10,163, doi:10.1002/2016GL070418.

Received 12 JUL 2016 Accepted 19 SEP 2016 Accepted article online 20 SEP 2016 Published online 9 OCT 2016

\section{Geological structures control on earthquake ruptures: The $M_{w} 7.7,2013$, Balochistan earthquake, Pakistan}

\author{
A. Vallage ${ }^{1}$, Y. Klinger ${ }^{1}$, R. Lacassin ${ }^{1}$, A. Delorme ${ }^{1}$, and M. Pierrot-Deseilligny ${ }^{2}$ \\ ${ }^{1}$ Institut de Physique du Globe de Paris, Sorbonne Paris Cité, Université Paris Diderot, UMR 7154, CNRS, Paris, France, ${ }^{2}$ IGN, \\ LASTIG, Université Paris-Est, Saint-Mandé, France
}

\begin{abstract}
The $2013 M_{w} 7.7$ Balochistan earthquake, Pakistan, ruptured the Hoshab fault. Left-lateral motion dominated the deformation pattern, although significant vertical motion is found along the southern part of the rupture. Correlation of high-resolution $(2.5 \mathrm{~m})$ optical satellite images provided horizontal displacement along the entire rupture. In parallel, we mapped the ground rupture geometry at 1:500 scale. We show that the azimuth of the ground rupture distributes mainly between two directions, $\mathrm{N} 216^{\circ}$ and $\mathrm{N} 259^{\circ}$. The direction $\mathrm{N} 216^{\circ}$ matches the direction of preexisting geologic structures resulting from penetrative deformation caused by the nearby Makran subduction. Hence, during a significant part of its rupture, the 2013 Balochistan rupture kept switching between a long-term fault front and secondary branches, in which existence and direction are related to the compressional context. It shows unambiguous direct interactions between different preexisting geologic structures, regional stress, and dynamic-rupture stress, which controlled earthquake propagation path.
\end{abstract}

\section{Introduction}

Major active faults are zones of weakness that bound tectonic plates and accommodate a large part of the relative plate motion [Bird, 2003]. However, boundary conditions driving plate tectonics evolve through time, involving continuous reconfiguration of the general plate tectonic scheme. As well, at the scale of plate boundaries, faults may deform and rotate because of long-term deformation propagation. Fault systems that were active once eventually become inactive tectonic scars in a new crustal collage. However, according to the current regional state of stress, these past tectonic structures can be reactivated and accommodate some deformation. Indeed, these structures are not necessarily perfectly oriented relatively to the current stress conditions, which results in possible changes of style of deformation, oblique slip, tectonic partitioning, and distributed deformation [Armijo et al., 1986; Bowman et al., 2003; Fitch, 1972; King et al., 2005; McCaffrey, 1992; Vallage et al., 2014]. It has been shown, for example, that major suture zones corresponding to past collision zones have facilitated later localization of tectonic structures currently acting as large strike-slip faults, such as in Tibet [Tapponnier et al., 2001], or along the North Anatolian fault [Armijo et al., 1999]. Similarly, some strike-slip faults have occasionally reverse sense of motion through time, to accommodate major change in tectonic plate configuration [Tapponnier et al., 1982; Landgraf et al., 2009].

Here we show that at the time scale of a singular earthquake too, we can identify the effect of preexisting geologic structures on the propagation of an earthquake rupture. In order to do that, one needs to be able to investigate in detail the rupture process. In the last decade, significant improvement of satellite imagery has allowed mapping in great detail existing faults distributed over the world and exploring complexity of earthquake surface ruptures [Klinger, 2010; Klinger et al., 2006; Wesnousky, 2006, 2008]. More specifically, the use of pre-earthquake and post-earthquake images together with image correlation technics makes possible to measure at high resolution the horizontal displacement field associated with an earthquake [Van Puymbroeck et al., 2000]. In few cases, combining such measurements with interferometric synthetic aperture radar allowed accessing the full 3-D surface deformation field and slip at depth [Fialko et al., 2001; Grandin et al., 2009; Vallage et al., 2015]. Using such techniques, Klinger et al. [2006] pointed to variations of amplitude of horizontal displacements along strike for the $M_{w} 7.8,2001$, Kunlun strike-slip event. Those variations are related to surficial geometrical complexities, evidencing at-depth fault segmentation at the scale of 10 to $20 \mathrm{~km}$ [Wei et al., 2011]. Such complexities of earthquake ruptures can make identification and measurement of the total coseismic displacement difficult, as they result in some distribution of the surficial deformation within the width of the fault zone. 
The $2013 M_{w} 7.7$ Balochistan earthquake occurred on the eastern part of the Makran accretionary wedge, Pakistan (Figure 1a) [Avouac et al., 2014; Barnhart et al., 2014, 2015; Jolivet et al., 2014; Zinke et al., 2014]. The Makran wedge corresponds to the convergence zone between Arabia in the south and Eurasia in the north. The rate of convergence is $\sim 3 \mathrm{~cm} / \mathrm{yr}$ [Reilinger et al., 2006]. Penetrative shortening affects the Tertiary rocks, which compose part of the Makran accretionary wedge. As a result, they are heavily folded and conjugate strike-slip faults, oriented $\pm 45^{\circ}$ to the main compressional direction, crosscut and offset the folds [Lawrence et al., 1981; Panagos et al., 2011]. To the northeast, the Chaman fault system accommodates the relative left-lateral motion between India and Eurasia at about $3 \mathrm{~cm} / \mathrm{yr}$ [Ambraseys and Bilham, 2003; Mohadjer et al., 2010; Reilinger et al., 2006; Szeliga et al., 2012]. The 2013, $M_{w} 7.7$, Balochistan earthquake ruptured $200 \mathrm{~km}$ of the Hoshab thrust, a fault connecting the area dominated by compression to the west, and the strike-slip fault system to the northeast.

The rich satellite imagery coverage (optical and radar) of the 2013 earthquake rupture, combined with arid climatic conditions, offers an opportunity to look in detail at the ground rupture patterns and deformation associated with this event. Large-scale kinks and jogs have seemed to control part of the rupture [Gold et al., 2015; Zinke et al., 2014]. In some sections, due to relative obliquity of the fault zone with boundary conditions, the surface displacement field indicates that a significant part of the deformation is distributed in a band associated to shallowing of the fault plane when reaching the surface [Vallage et al., 2015]. Band's width varies along strike, in part due to the presence, or not, of loose sediments. The existence of such band of distributed deformation, mostly located in the hanging wall, results in significant differences in the amount of horizontal displacement that could be measured in the direct vicinity of the rupture and away from the fault, at distances of $1 \mathrm{~km}$ to several kilometers [Barnhart et al., 2015; Gold et al., 2015; Vallage et al., 2015; Zinke et al., 2014].

In this paper, based on detailed mapping of the surface rupture at the scale 1:500, and on measurements of the horizontal displacement derived from high-resolution optical satellite images correlation, we show that the total amount of displacement is preserved when one gets close to the rupture. However, along some sections, rotation occurs that promotes fault-normal displacement instead of fault-parallel displacement, making it more difficult to quantify the total displacement. These local rotations of the direction of motion are related to small changes in the azimuth of the rupture, which are quantified, based on our general rupture map. Eventually, we show that these changes in azimuth of the propagating rupture during the earthquake are controlled in large part by geologic structures that predate the 2013 earthquake.

\section{Materials and Methods}

Because field measurements are currently impossible in the area of the $M_{w} 7.7,2013$, Balochistan earthquake, we had to rely on spatial geodesy to investigate the geometry of the rupture. Previous works, based on seismological and radar data, provided information about the rupture at depth but were limited in resolution about surficial deformation in the direct vicinity of the rupture [Avouac et al., 2014; Jolivet et al., 2014]. Several studies, however, using mostly post-earthquake optical imagery focused on surficial deformation patterns, pointed to first-order geometrical discontinuities and variability of the slip distribution [Barnhart et al., 2014, 2015; Gold et al., 2015; Vallage et al., 2015; Zhou et al., 2015; Zinke et al., 2014].

Here we correlate five pairs of optical satellite images from SPOT-5 and two pairs of Landsat 8 images. Each pair includes one image acquired before the earthquake and a second image acquired after the event. Both SPOT-5 and Landsat 8 data sets cover the entire rupture area associated with the 2013 earthquake. Correlation of each pair of images was performed using the open-source software MicMac [Rosu et al., 2014; http://logiciels.ign.fr/?Micmac]. Details on image processing and associated corrections can be found in Vallage et al. [2015]. Eventually, the optical images correlation provides us with a continuous horizontal coseismic displacement field, including in the fault zone, with a ground pixel size of $2.5 \mathrm{~m}$ (Figure 1b).

In parallel to displacement measurements based on image correlation, we mapped the surface rupture using 21 postearthquake WorldView optical satellite images complemented by high-resolution images freely available on Google Earth ${ }^{\mathrm{TM}}$. These images are characterized by their high resolution (ground pixel size $\leq 1 \mathrm{~m}$ ) that allows mapping any crack about the size of a few pixels. Using the Google Earth functionalities to display image time series, we were able to unambiguously decipher 2013 coseismic ruptures from older ruptures 


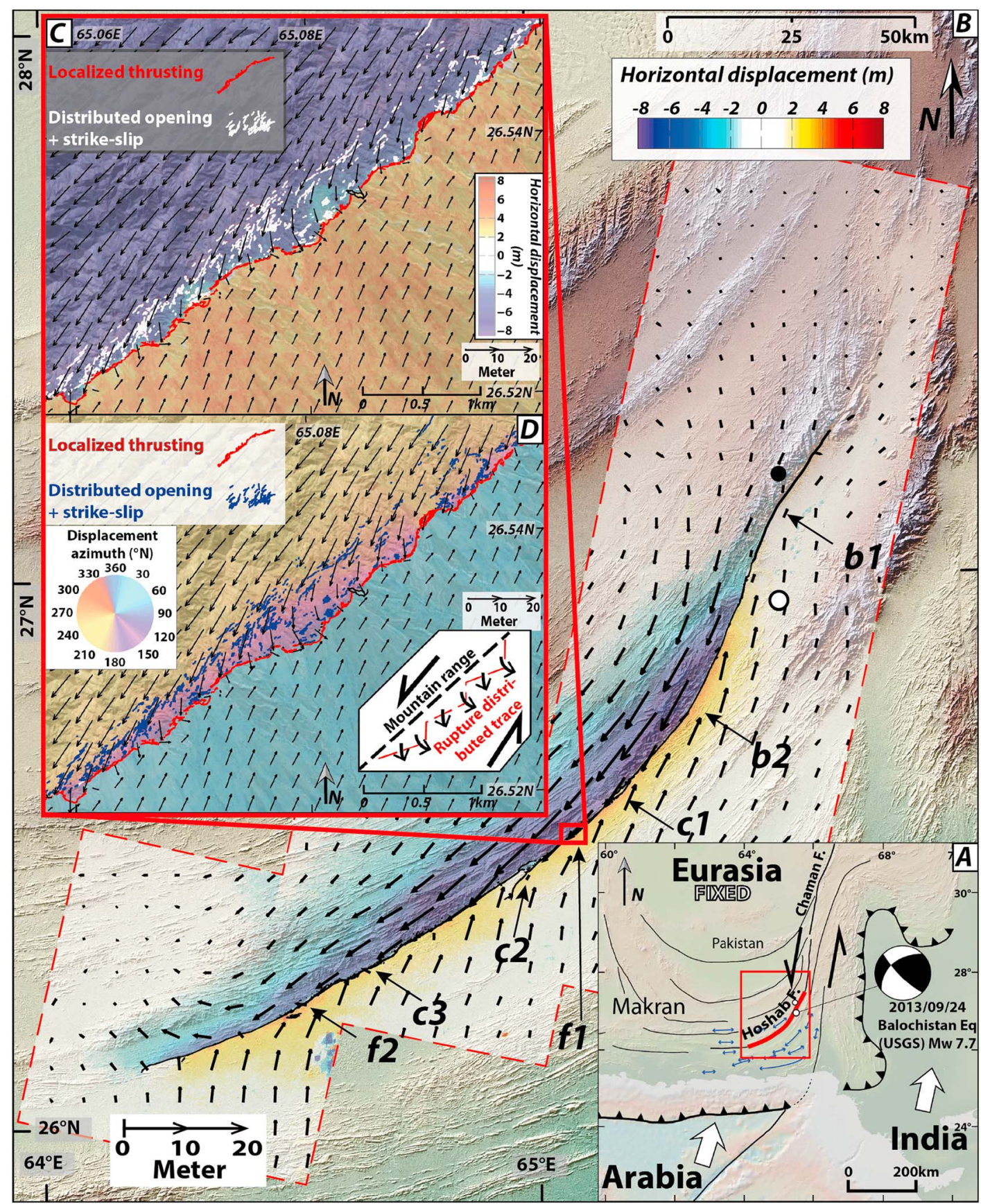

Figure 1. (a) Regional context of the 2013 Balochistan earthquake from Avouac et al. [2014], Ader et al. [2012], and Reilinger et al. [2006]. The earthquake ruptured the Hoshab fault that connects the Makran thrusts with the left-lateral Chaman fault system. Orientations of main folds in Tertiary rocks are in blue. The red footprint corresponds to Figure 1b. (b) SPOT-5 horizontal displacement field with $2.5 \mathrm{~m}$ ground resolution superimposed on Advanced Spaceborne Thermal Emission and Reflection Radiometer (ASTER) digital elevation model (30 m pixel). Displacements toward SW and NE are, respectively, represented negative bluish and positive yellowish. White and black circles correspond to U.S. Geological Survey epicenter location for the $M_{w} 7.7$ earthquake and for the main $M_{w} 6.6$ aftershock, respectively. b1, b2, c1, c2, and c3 indicate the main kilometric-size surface asperities. f1 and f2 correspond to sharp bends and en echelon cracks at hundred meter scale.

(c) Example of local complex coseismic ground rupture (part of zone f1): amplitude of horizontal displacement is preserved up to the localized thrust mapped directly from imagery. Same color code as Figure 1b. (d) Azimuth of displacement. Purple colors highlight the transfer from strike-slip-dominated to shortening-dominated displacement inside the damage zone, correlated with numerous tensile cracks in the hanging wall, shown in blue. Vector field superimposed to emphasize the small-scale block rotation. 


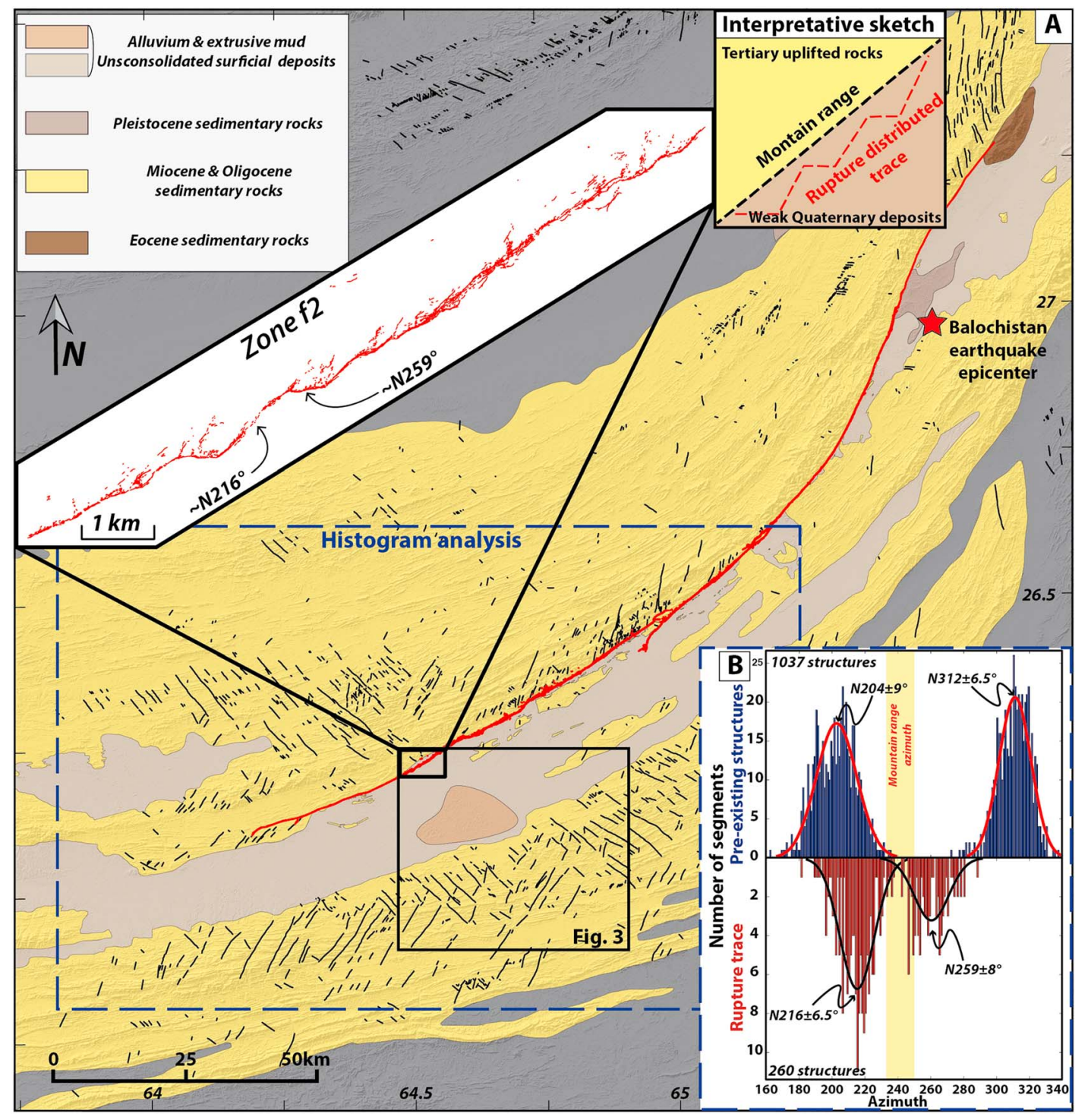

Figure 2. (a) Geological map around the Balochistan rupture adapted from Panagos et al. [2011]. Preexisting faults are mapped in black, based on first observations by Lawrence et al. [1981]. Zoom in the inset presents the distribution of ground rupture in the zone $\mathrm{f} 2$, with the two main azimuths indicated. The blue dashed box corresponds to the area where we measured the preexisting structures and the coseismic rupture azimuths. (b) Bimodal distribution of coseismic ground rupture azimuths (in red), bimodal distribution of preexisting faults azimuths (blue) and mountain range azimuth (yellow). The group of coseismic azimuths centered at $\mathrm{N} 216^{\circ}$ matches preexisting structures with azimuths centered at $\mathrm{N} 204^{\circ}$ rather than the Hoshab thrust orientation.

to produce a coseismic surface rupture map at the 1:500 scale along most of the $200 \mathrm{~km}$ long ground rupture (Figures $1 \mathrm{~b}$ and 2; digital map in the supporting information). This map provides a unique data set to geometrically characterize the rupture and to quantify variation of the rupture azimuth at different spatial scales along strike. In addition, available images at larger scale, along with regional topography, were used to map the regional long-term fault structures present in Balochistan, that were not necessarily directly activated during the event, although they might have influenced the fate of the rupture.

\section{Results}

\subsection{Coseismic Deformation}

The 2013, $M_{w} 7.7$, Balochistan earthquake propagated mainly southward from the epicentral area, over $160 \mathrm{~km}$. North of the epicenter, the rupture is only $40 \mathrm{~km}$ long, and the displacement remains smaller than $4 \mathrm{~m}$. The maximum value for horizontal displacement, $14 \mathrm{~m}$, is located about $50 \mathrm{~km}$ south of the epicenter, 
where the fault trace veers to the southwest, at the bend b2 (Figure $1 \mathrm{~b}$ ). Then, the horizontal slip remains larger than $6 \mathrm{~m}$ almost until the end of the rupture [Vallage et al., 2015]. In addition to two major bends b1 and b2, three kilometric-size geometrical complexities affect the southern part of the rupture, which are two relay zones $c 1$ and $c 2$, and a paired bend c3 (Figure 1b).

Very limited changes in ground conditions through time, and high resolution of SPOT-5 images, $2.5 \mathrm{~m}$, ensure exceptional conditions for multitemporal image correlation. Thus, it allows measuring the coseismic deformation field very close to the actual fault, to a distance of a few pixels from the ground rupture, and to estimate the total ground-deformation budget. Figure 1c presents the zone $\mathrm{f} 1$ that was previously identified as a zone where deformation is partly distributed, with a sharp thrust front limiting the zone of rupture to the east, and a more diffuse mixture of extension and strike-slip motion in the hanging wall [Vallage et al., 2015]. In that area, interpretation of post-earthquake imagery led Zinke et al. [2014] to suggest the existence of local deficit in surficial strike-slip motion, in comparison to what would be expected from far-field displacement. In fact, a small drop in the amplitude of the total horizontal displacement, which includes both fault-normal and faultparallel displacement, is visible in the area where ground rupture gets wider. This drop is indicated by a change from deep purple to bluish hue in Figure 1c. This change corresponds to the part of the slip that is accommodated by the strike-slip and normal faults, marked in white in the hanging wall (Figure 1c). Most of the displacement, however, as indicated by the sharp color change at the frontal scarp (Figure 1c), is accommodated on the frontal scarp without significant loss. To reconcile the deficit of strike slip deduced from photointerpretation and the fact that the total amplitude of displacement is not decreasing significantly, we plotted the azimuth of the displacement for each point of the displacement field (Figure 1d). Away from the fault, as expected, displacement is mostly parallel to the fault, with a slight component of shortening. This behavior is true everywhere in the footwall. In the hanging wall, however, the picture is different. Away from the fault zone, the displacement is oriented almost parallel to the displacement in the footwall, although in the opposite direction (yellow and blue in Figure 1d). However, closer to the fault zone, the direction of displacement is quickly changing to become oblique to the fault scarp (pink in Figure 1d), which is consistent with the thrust component evidenced from spatial geodesy [Gold et al., 2015; Jolivet et al., 2014; Vallage et al., 2015; Zhou et al., 2015] and also from the few field observations available [Hudnut et al., 2013]. Hence, to get the total displacement budget in this area, it is necessary to cumulate both the strike-slip and the thrust components. Such behavior suggests that some block rotation occurs in the hanging wall, which accommodates complex local 3-D deformation. This behavior can be observed in many places, from the bend b2 to the SW termination of the rupture. Along this section the geometry of the rupture scarp is actually characterized by a peculiar geometry. Instead of following the general fault azimuth that roughly parallels the mountain front, the scarp geometry is characterized by series of abrupt azimuthal changes where the scarp is breaking through loose sediment (Figures 1d and 2). Using the detailed map of the rupture (Figure $1 \mathrm{~b}$ and the supporting information), we have systematically measured the local azimuth of the rupture south of b2 (Figure $2 b$ ), taking the average azimuth of each straight section along strike, although we restricted ourselves to sections at least $100 \mathrm{~m}$ long. The distribution of azimuth is bimodal. The largest group of azimuths is centered on $\mathrm{N} 216^{\circ} \pm 6.5^{\circ}$. The second group of azimuths peaks at $\mathrm{N} 259^{\circ} \pm 8^{\circ}$. Interestingly, none of these two peaks corresponds to the azimuth of the mountain front, which varies from $\mathrm{N} 232^{\circ}$ to $\mathrm{N} 251^{\circ}$ when moving southward along the fault (Figure $2 \mathrm{~b}$ ). Therefore, although at large scale the earthquake rupture seems to follow the active fault trace, and longer-term mountain front, in details it appears that along most of the rupture the azimuth of coseismic rupture actually varies around the azimuth of the mountain front, but never really matches it.

\subsection{Regional Tectonic Deformation}

At the regional scale, a succession of thrusts and folds forms the aerial part of the Makran accretionary wedge [Platt et al., 1985, 1988; Smith et al., 2012]. These thrust faults, including the Hoshab fault, accommodate folding at kilometric scale, which affects the local basement formed by Tertiary rocks. Although exact dating of this folding is not well constrained, it is worth noting that many of these folds are significantly eroded and might not all be active at the moment. Similarly, evidence of recent earthquake activity along the Hoshab fault itself is also limited [Zhou et al., 2015]. Aside from folding perpendicular to the maximum compressional direction, the area is also characterized by penetrative horizontal shear along a direction $\pm 45^{\circ}$ from the main compressional direction. Although this deformation is probably affecting the entire massif, in some places 


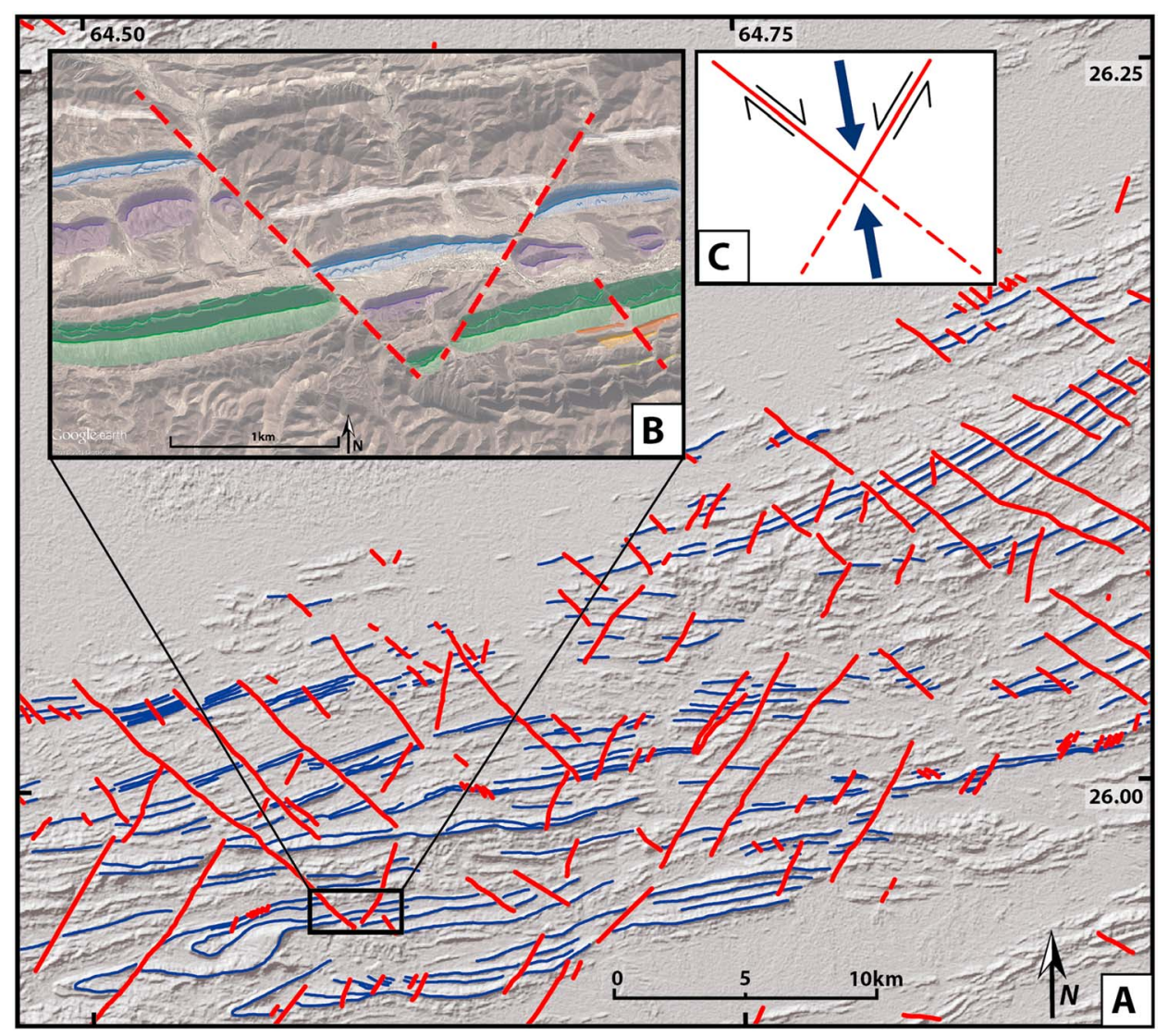

Figure 3. (a) Zoom on the $30 \mathrm{~m}$ ground resolution ASTER digital elevation model with mountain crests highlighted in blue, strike-slip faults are mapped in red. (b) Detail from Google Earth imagery with color-coded crests according to their different facies. (c) Interpretative sketch for the conjugated strike-slip faults, indicative of approximately N-S shortening affecting penetratively the Makran wedge north of the subduction front, located $200 \mathrm{~km}$ farther south (see Figure 1).

deformation localizes along strike-slip structures that eventually offset the Tertiary rock folds in a visible manner (Figure 3) [Lawrence et al., 1981]. These structures are not visible in the basins filled with Quaternary sediments, but it is likely that they affect the basement everywhere in the area. Because they are conjugate structures, strike-slip faults oriented NE-SW and NW-SE are left lateral and right lateral, respectively. These structures do not exceed few kilometers in length, with a maximum of about $10 \mathrm{~km}$. Total offset on each structure, variable along strike, is usually few hundreds of meters and at most $1-2 \mathrm{~km}$.

From high-resolution images, we systematically mapped offset landforms, such as folds, at regional scale (Figure 3) around the Hoshab fault. For each fault identified, we also measured its azimuth (Figure 2b, blue distribution). As expected for a set of conjugated faults, the azimuth distribution is bimodal, with one group centered on the direction $\mathrm{N}^{204^{\circ}} \pm 9^{\circ}$, and the second group centered on the direction $\mathrm{N} 312^{\circ} \pm 6.5^{\circ}$. Following a classic Coulomb fracture criterion approach, these two directions define the local direction of maximum horizontal stress $\sigma 1$ to be $\mathrm{N} 168^{\circ}$, about $32^{\circ}$ from each faults group azimuth. This is consistent with the general orientation of folds in the area used for azimuth measurement (Figure 2), as well as with the rough northsouth direction of regional convergence.

\section{Discussion}

Although it has been shown that along several sections of the Hoshab rupture the deformation is distributed in a wide damage zone [Zinke et al., 2014; Gold et al., 2015; Vallage et al., 2015], our measurements indicate that the amplitude of the coseismic displacement is almost fully preserved up to the frontal thrust, due to block rotations in the hanging wall. These rotations are associated with small-scale (hundreds of meters) local variations of azimuth of the frontal thrust, which deviates from the overall azimuth of the mountain front, 


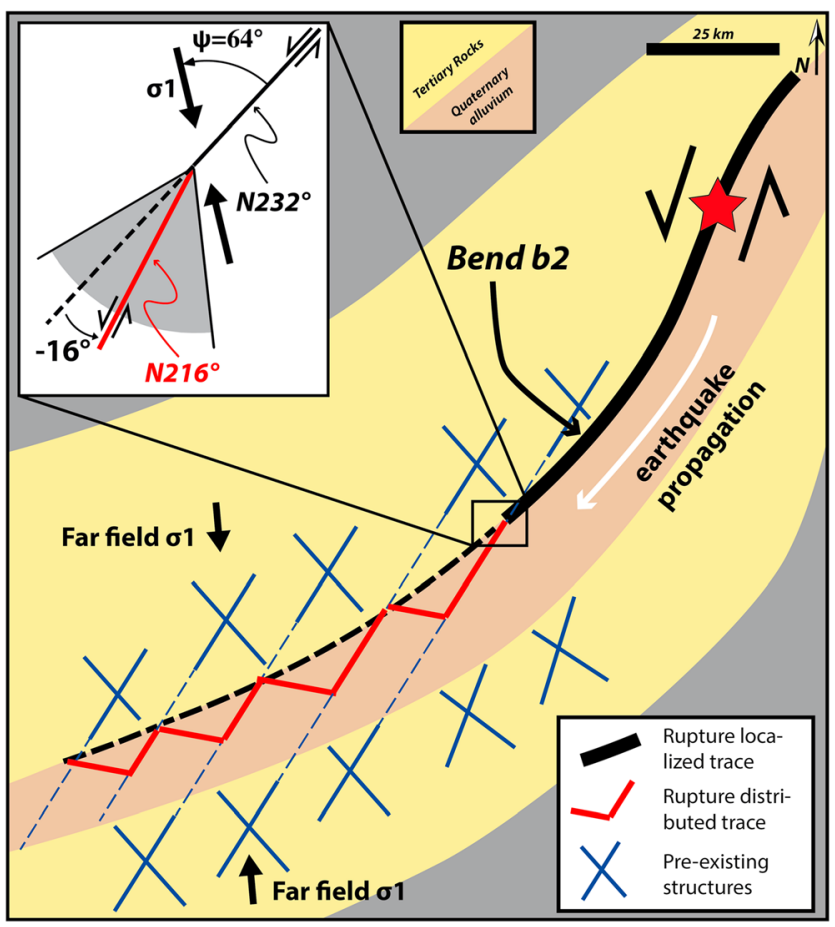

Figure 4. Conceptual scenario that reconciles the different observations along the rupture length and the specific correlation between one direction of coseismic frontal scarp and one direction of the preexisting geological structures. Inset shows detail of the branching process, based on Kame et al. [2003], where values have been adapted to reflect the 2013 Balochistan configuration. pagation of the earthquake, at least the uppermost kilometer of the rupture was systematically branching off the mountain front, along a direction dictated by the local tectonic fabric related to long-term penetrative deformation. This is actually consistent with the fact that for a left-lateral strike-slip rupture, in an environment where the regional horizontal stress makes a large angle $\left(>45^{\circ}\right)$ with the direction of the rupture propagation, the lobe of maximum dynamic elastic stress propagating ahead of the rupture is oriented obliquely to the rupture direction, in the dilatational quadrant, and thus it favors branching in this quadrant [Poliakov et al., 2002; Kame et al., 2003], especially if planes of weakness already exist. In the case of the Balochistan rupture, the rupture does not succeed to propagate over a large distance on the branch and quickly reconnects to the long-term fault that runs closer to the mountain front. One reason for such oscillation might be related to the different stress configuration along the mountain front fault and on the branch. While the rupture is propagating along a direction close to the mountain front, the fault is more and more oblique to the principal horizontal stress direction and branching will be favored in the dilatational quadrant [Poliakov et al., 2002]. Conversely, as soon as the rupture is propagating along the branch, the angle between the branch and the principal horizontal stress direction decreases. In such condition Poliakov et al. [2002] show that rupture could then be promoted in both the dilatational and the compressional quadrants, which in our case would favor a rupture reconnecting to the mountain front (Figure 4). Indeed, full propagation along branches is probably hindered by the fact that the shear fabric, although affecting the entire basement, has not developed into long continuous structures able to host a sizable earthquake.

Major improvement in our ability to map ground rupture and coseismic displacement open new avenues to understand rupture patterns directly related to rupture propagation. In the case of the Balochistan earthquake, the rupture initiated in the northern part of the Hoshab fault as a strike slip and propagated southward along a fault that becomes less and less favorable for strike-slip motion onward. Detailed mapping of the rupture indicates that the ground pattern of rupture is very complex. As shown in the previous section, the complexity of the rupture is not random, but the rupture follows a path mostly controlled by the penetrative tectonic fabric preexisting the earthquake. The impact of such preexisting geological structures on the way 
an earthquake rupture proceeds has already been suggested several times, although it was never fully demonstrated. During the $1995 M_{w} 7.3$ Landers earthquake, the rupture propagated through a set of fault segments that show two dominant directions consistent with the directions of the major structures in the East California Shear zone [Dokka and Travis, 1990]. Similarly, the lateral extent of the $1983 M_{s} 7.3$ Borah Peak normal fault earthquake seems to have been controlled by the preexistence of cross faults [Susong et al., 1990]. Eventually, it has been suggested that depending on geometrical configuration of preexisting geological structures, branching could be systematic, such as during the 1939 Erzincan earthquake, in Turkey; the 2001 Kokoxili earthquake, in China; or the 2002 Denali earthquake in Alaska [Barka, 1996; Bhat et al., 2004; Klinger et al., 2006]. Because the crust is full of preexisting structures that are possible paths for an ongoing rupture, depending on the local stress condition, any rupture is likely to be complex. Hence, this could question the assumption that faults have to become smoother with time [Wesnousky, 1988] as each earthquake rupture recreates some level of complexity [Klinger, 2010] due to interaction between propagating rupture and preexisting geologic structures.

\section{Acknowledgments}

We thank CNES ISIS and TOSCA programs and International Charter "Space and Major Disaster" for access to SPOT-5 and WorldView imagery, respectively. Numerical computations were performed on the S-CAPAD platform, IPGP, France. Rupture map in the supporting information. This work is supported by ANR GeoSMEC contract ANR-12-BS06-0016. We thank A.V. Newman, S. Kübler, and G. Peltzer for insightful comments. This is IPGP contribution 3786 .

\section{References}

Ader, T., et al. (2012), Convergence rate across the Nepal Himalaya and interseismic coupling on the Main Himalayan Thrust: Implications for seismic hazard, J. Geophys. Res., 117, B04403, doi:10.1029/2011JB009071.

Ambraseys, N., and R. Bilham (2003), Earthquakes in Afghanistan, Seismol. Res. Lett., 74, 107-123.

Armijo, R., P. Tapponnier, J. L. Mercier, and H. Tong-Lin (1986), Quaternary extension in Southern Tibet: Field observations and tectonic implications, J. Geophys. Res., 91, 13,803-13,872, doi:10.1029/JB091iB14p13803.

Armijo, R., B. Meyer, A. Hubert, and A. Barka (1999), Westward propagation of the North Anatolian fault into the northern Aegean: Timing and kinematics, Geology, 27, 267-270.

Avouac, J. P., F. Ayoub, S. Wei, J. P. Ampuero, L. Meng, S. Leprince, R. Jolivet, Z. Duputel, and D. Helmberger (2014), The 2013, Mw 7.7 Balochistan earthquake, energetic strike-slip reactivation of a thrust fault, Earth Planet. Sci. Lett., 391, 128-134.

Barka, A. (1996), Slip distribution along the North Anatolian fault associated with the large earthquakes of the period 1939-1967, Bull. Seismol. Soc. Am., 86, 1238-1254.

Barnhart, W. D., G. P. Hayes, R. W. Briggs, R. D. Gold, and R. Bilham (2014), Ball-and-socket tectonic rotation during the $2013 M_{w} 7.7$ Balochistan earthquake, Earth Planet. Sci. Lett., 403, 210-216.

Barnhart, W. D., R. W. Briggs, N. G. Reitman, R. D. Gold, and G. P. Hayes (2015), Evidence for slip partitioning and bimodal slip behavior on a single fault: Surface slip characteristics of the $2013 M_{w} 7.7$ Balochistan, Pakistan earthquake, Earth Planet. Sci. Lett., 420, 1-11.

Bhat, H., R. Dmowska, J. Rice, and N. Kame (2004), Dynamic slip transfer from the Denali to Totschunda faults, Alaska: Testing theory for fault branching, Bull. Seismol. Soc. Am., 94, S202-S213.

Bird, P. (2003), An updated digital model of plate boundaries, Geochem. Geophys. Geosyst., 4(3), 1027, doi:10.1029/2001GC000252.

Bowman, D., G. King, and P. Tapponnier (2003), Slip partitioning by elastoplastic propagation of oblique slip at depth, Science, 300, 1121-1123.

Dokka, R., and C. Travis (1990), Late Cenozoic strike-slip faulting in the Mojave Desert, California, Tectonics, 9, 311-340, doi:10.1029/ TC009i002p00311.

Fialko, Y., M. Simons, and D. Agnew (2001), The complete (3-D) surface displacement field in the epicentral area of the $1999 M_{w} 7.1$ Hector Mine earthquake, California, from space geodetic observations, Geophys. Res. Lett., 28, 3063-3066, doi:10.1029/2001GL013174.

Fitch, T. (1972), Plate convergence, transcurrent faults, and internal deformation adjacent to Southeast Asia and the western Pacific, J. Geophys. Res., 77, 4432-4462, doi:10.1029/JB077i023p04432.

Gold, R. D., N. G. Reitman, R. W. Briggs, W. D. Barnhart, G. P. Hayes, and E. Wilson (2015), On- and off-fault deformation associated with the September $2013 M_{w} 7.7$ Balochistan earthquake: Implications for geologic slip rate measurements, Tectonophysics, doi:10.1016/ j.tecto.2015.08.019.

Grandin, R., et al. (2009), September 2005 Manda Hararo-Dabbahu rifting event, Afar (Ethiopia): Constraints provided by geodetic data, J. Geophys. Res., 114, B08404, doi:10.1029/2008JB005843.

Hudnut, K. W., S. D. Khan, F. Ayoub, S. Akciz, D. M. Kakar, M. U. Baloch, M. Shaph, and A. S. Khan (2013), Fault displacement from Landsat 8 pre- and post-earthquake image differencing and initial field observations of the surface rupture of the $M 7.7$ Awaran earthquake of 24 September 2013, Abstract S22C-0006 presented at 2013 Fall Meeting, AGU.

Jolivet, R., et al. (2014), The $2013 M_{w} 7.7$ Balochistan earthquake: Seismic potential of an accretionary wedge, Bull. Seismol. Soc. Am., 104, 1020-1030.

Kame, N., J. R. Rice, and R. Dmowska (2003), Effects of prestress state and rupture velocity on dynamic fault branching, J. Geophys. Res., 108(B5), 2265, doi:10.1029/2002JB002189.

King, G., Y. Klinger, D. Bowman, and P. Tapponnier (2005), Slip partitioned surface breaks for the 2001 Kokoxili earthquake, China $\left(M_{w} 7.8\right)$ Bull. Seismol. Soc. Am., 95, 731-738.

Klinger, Y. (2010), Relation between continental strike-slip earthquake segmentation and thickness of the crust, J. Geophys. Res., 115, B07306 doi:10.1029/2009JB006550.

Klinger, Y., R. Michel, and G. C. P. King (2006), Evidence for an earthquake barrier model from $M_{w}$ similar to 7.8 Kokoxili (Tibet) earthquake slip-distribution, Earth Planet. Sci. Lett., 242, 354-364.

Landgraf, A., P. Ballato, M. R. Strecker, A. Friedrich, S. H. Tabatabaei, and M. Shahpasandzadeh (2009), Fault-kinematic and geomorphic observations along the North Tehran Thrust and Mosha Fasham Fault, Alborz mountains Iran: Implications for fault-system evolution and interaction in a changing tectonic regime, Geophys. J. Int., 177, 676-690, doi:10.1111/j.1365-246X.2009.04089.x.

Lawrence, R. D., R. S. Yeats, S. H. Khan, A. Farah, and K. A. DeJong (1981), Thrust and strike slip fault interaction along the Chaman transform zone, Pakistan, Geol. Soc. London Spec. Publ., 9, 363-370.

McCaffrey, R. (1992), Oblique plate convergence, slip vectors, and forearc deformation, J. Geophys. Res., 97, 8905-8915, doi:10.1029/ 92JB00483. 
Mohadjer, S., et al. (2010), Partitioning of India-Eurasia convergence in the Pamir-Hindu Kush from GPS measurements, Geophys. Res. Lett., 37, L04305, doi:10.1029/2009GL041737.

Panagos, P., A. Jones, C. Bosco, and P. S. S. Kumar (2011), European digital archive on soil maps (EuDASM): Preserving important soil data for public free access, Int. J. Digital Earth, 4, 434-443.

Platt, J. P., J. K. Leggett, J. Young, H. Raza, and S. Alam (1985), Large-scale sediment underplating in the Makran accretionary prism, southwest Pakistan, Geology, 13, 507-511.

Platt, J. P., J. K. Leggett, and S. Alam (1988), Slip vectors and fault mechanics in the Makran accretionary wedge, southwest Pakistan, J. Geophys. Res., 93, 7955-7973, doi:10.1029/JB093iB07p07955.

Poliakov, A. N., R. Dmowska, and J. R. Rice (2002), Dynamic shear rupture interactions with fault bends and off-axis secondary faulting, J. Geophys. Res., 107(B11), 2295, doi:10.1029/2001JB000572.

Reilinger, R., et al. (2006), GPS constraints on continental deformation in the Africa-Arabia-Eurasia continental collision zone and implications for the dynamics of plate interactions, J. Geophys. Res., 111, B05411, doi:10.1029/2005JB004051.

Rosu, A.-M., M. Pierrot-Deseilligny, A. Delorme, R. Binet, and Y. Klinger (2014), Measurement of ground displacement from optical satellite image correlation using the free open-source software MicMac, ISPRS J. Photogramm. Remote Sens., 100, 48-59.

Smith, G., L. McNeill, T. J. Henstock, and J. Bull (2012), The structure and fault activity of the Makran accretionary prism, J. Geophys. Res., 117, B07407, doi:10.1029/2012JB009312.

Susong, D. D., S. U. Janecke, and R. L. Bruhn (1990), Structure of a fault segment boundary in the Lost River fault zone, Idaho, and possible effect on the 1983 Borah Peak earthquake rupture, Bull. Seismol. Soc. Am., 80, 57-68.

Szeliga, W., R. Bilham, D. M. Kakar, and S. H. Lodi (2012), Interseismic strain accumulation along the western boundary of the Indian subcontinent, J. Geophys. Res., 117, B08404, doi:10.1029/2011JB008822.

Tapponnier, P., G. Peltzer, A. Y. Le Dain, R. Armijo, and P. Cobbold (1982), Propagating extrusion tectonics in Asia: New insights from simple experiments with plasticine, Geology, 10, 611-616

Tapponnier, P., X. Zhiqin, F. Roger, B. Meyer, N. Arnaud, G. Wittlinger, and Y. Jingsui (2001), Oblique stepwise rise and growth of the Tibet Plateau, Science, 294, 1671-1677.

Vallage, A., M. H. Deves, Y. Klinger, G. C. P. King, and N. A. Ruppert (2014), Localized slip and distributed deformation in oblique settings: The example of the Denali fault system, Alaska, Geophys. J. Int., 197, 1284-1298.

Vallage, A., Y. Klinger, R. Grandin, H. S. Bhat, and M. Pierrot-Deseilligny (2015), Inelastic surface deformation during the $2013 M_{w} 7.7$ Balochistan, Pakistan, earthquake, Geology, 43, 1079-1082.

Van Puymbroeck, N., R. Michel, R. Binet, J. P. Avouac, and J. Taboury (2000), Measuring earthquakes from optical satellite images, Appl. Opt., 39, 3486-3494.

Wei, S., et al. (2011), Surficial simplicity of the 2010 El Mayor-Cucapah earthquake of Baja California in Mexico, Nat. Geosci., 4, 615-618.

Wesnousky, S. (2006), Predicting the endpoints of earthquake ruptures, Nature, 444, 358-360.

Wesnousky, S. (2008), Displacement and geometrical characteristics of earthquake surface ruptures: Issues and implications for seismic-hazard analysis and the process of earthquake rupture, Bull. Seismol. Soc. Am., 98, 1609-1632.

Wesnousky, S. G. (1988), Seismological and structural evolution of strike-slip faults, Nature, 335, 340-343.

Zhou, Y., J. R. Elliott, B. Parsons, and R. T. Walker (2015), The 2013 Balochistan earthquake: An extraordinary or completely ordinary event?, Geophys. Res. Lett., 42, 6236-6243, doi:10.1002/2015GL065096.

Zinke, R., J. Hollingsworth, and J. F. Dolan (2014), Surface slip and off-fault deformation patterns in the 2013 MW7.7 Balochistan, Pakistan earthquake: Implications for controls on the distribution of near-surface coseismic slip, Geochem. Geophys. Geosyst., 15, 5034-5050, doi:10.1002/2014GC005538. 